\title{
Autologous Mixed Lymphocyte Reaction in the Peripheral Blood and Pleural Effusions of Cancer Patients
}

\author{
Atsushi Uchida and Michael Micksche, Institute for Cancer Research, \\ University of Vienna, A-1090 Vienna, Austria
}

A B S T R A C T T cells proliferate in response to autologous non-T cells in the autologous mixed lymphocyte reaction (AMLR). AMLR was impaired in the peripheral blood of patients with advanced lung cancer $(4,159 \pm 3,878 \Delta \mathrm{cpm}$ vs. $11,221 \pm 4,156 \Delta \mathrm{cpm}$ for normal donors) but normal or even higher in their malignant pleural effusions $(13,257 \pm 7,075 \Delta$ cpm vs. $10,870 \pm 5,013 \Delta \mathrm{cpm}$ for nonmalignant control effusions). Blood $\mathrm{T}$ cells also failed to respond to autologous effusion non- $T$ cells, while effusion $T$ cells strongly responded to autologous blood non-T cells. The presence of blood T cells did not inhibit effusion AMLR of the same patients. A subset of $\mathrm{T}$ cells that form rosettes with autologous erythrocytes is found to proliferate in AMLR. The number of autorosette-forming cells was lower in blood $T$ cells of cancer patients than in blood $T$ cells of normal donors and in effusion $T$ cells of the patients. After enrichment of autorosetteforming cells, there was no difference in AMLR of normal blood and cancer blood and effusions. These results indicate that the loss of AMLR in the blood of cancer patients is due to a reduction of number of autoreactive $T$ cells and not to a defect of autologous stimulator non- $\mathrm{T}$ cells.

\section{INTRODUCTION}

The depression of cell-mediated immunity, demonstrated by various in vivo and in vitro assays, is known to be associated with malignancy $(1,2)$. Patients with lung cancer have been shown to have impairment of lymphoproliferative response to mitogens and alloantigens $(3,4)$. Some of these defects appear to be due to the presence of suppressor cells in the circulation (5-8). These findings suggest that immunoregulatory functions might be disturbed in cancer patients.

There is increasing evidence that a subpopulation of human non-T cells stimulates the proliferation of autologous $\mathrm{T}$ cells in the autologous mixed lymphocyte

Received for publication 12 August 1981 and in revised form 23 February 1982. reaction $(A M L R)^{1}(9,10)$. Although the biologic significance of this phenomenon is not yet clarified, the reaction can be demonstrated reproducibly in normal individuals and exhibits immunologic memory and specificity (11). The AMLR has been demonstrated to represent a natural defense mechanism against neoplastic transformation (12), to provide a proliferative stimulus for the generation of cytotoxic lymphocytes (11), and to regulate various immunologic functions such as production of antibody by B cells (13) and T cell response to mitogens and antigens $(14,15)$. Although there is general agreement that the responding population in the AMLR is T cells, the nature of the stimulator cells has been reported variously as B cells (10), null cells (16), and monocytes (17). It has recently been demonstrated that a subset of $T$ cells that can form rosettes with autologous erythrocytes is involved in the $\operatorname{AMLR}(18,19)$ and concanavalin A-induced suppressor cell function (18).

The impairment of AMLR has been documented in patients with systemic lupus erythematosus $(20,21)$, chronic lymphocytic leukemia (22), Hodgkin's disease (23), and Sjögren's syndrome (24). It is difficult to know which cell population is responsible for the depression of AMLR because both responding and stimulating cells are from the same patients and therefore $T$ cells and non- $T$ cells from healthy individuals with HLA-A, B, and DR locus identical to each patients' are required for exact determination. Our study was designed to investigate the AMLR in the peripheral blood and pleural effusions of patients with advanced lung cancer as well as to characterize the cells involved in the depression of blood AMLR.

\section{METHODS}

Patient population. Peripheral blood and pleural effusions were obtained from 20 patients with carcinomatous

${ }^{1}$ Abbreviations used in this paper: AMLR, autologous mixed lymphocyte reaction; $\Delta \mathrm{cpm}$, difference between the counts per minute of responding cells in the presence and absence of stimulation cells. 
pleural effusions in which the presence of tumor cells were confirmed with routine cytologic techniques by independent pathologists. The 13 male and 7 female patients ranging in age from 31 to $50 \mathrm{yr}$ were histologically diagnosed as having lung carcinoma. No patients had had previous anticancer therapy. Eff usion specimens from eight patients with congestive heart failure were studied as controls for the pleural effusions. Peripheral blood specimens of 20 healthy normal donors were used as roughly age- and sex-matched controls for the peripheral blood.

Isolation of blood mononuclear cells. Lymphocyte-rich mononuclear cells were isolated from 50 to $80 \mathrm{ml}$ heparinized peripheral blood by centrifugation on a Ficoll-Hypaque gradient (Lymphoprep, sp g 1.077, Nyegaard \& Co., Oslo, Norway) (25). The mononuclear cells were collected from the interface, washed, and resuspended in RMPI 1640 supplemented with $2 \mathrm{mM}$ L-glutamine, $25 \mathrm{mM}$ Hepes, $100 \mathrm{U}$ penicillin $/ \mathrm{ml}, 100 \mu \mathrm{g}$ streptomycin $/ \mathrm{ml}$, and $10 \%$ heat-inactivated fetal calf serum [Gibco Bio-Cult, Glasgow, Scotland (designated as complete medium)].

Isolation of effusion mononuclear cells. Specimens of pleural effusions (500-1,000 ml) were obtained from the patients by thoracentesis and immediately centrifuged at $400 \mathrm{~g}$ for $10 \mathrm{~min}$. The cell pellet was then washed five times, and the cells were adjusted at a concentration of $1 \times 10^{6} \%$ $\mathrm{ml}$ in complete medium. This cell suspension was layered on a discontinuous gradient consisting of $10 \mathrm{ml}$ of $100 \%$ and $15 \mathrm{ml}$ of $75 \%$ Ficoll-Hypaque in a $50-\mathrm{ml}$ plastic tube (Falcon Labware, Div. of Becton Dickinson \& Co., Oxnard, CA), and centrifuged at $400 \mathrm{~g}$ for $30 \mathrm{~min}$ at room temperature, as described $(26,27)$. Lymphocyte-rich mononuclear cells were collected from the $100 \%$ interface, tumor, and mesothelial cells from the $\mathbf{7 5 \%}$ interface, and erythrocytes, polymorphonuclear cells, and aggregated tumor cells from the bottom. The procedure was repeated one to four times if separation was not successful as judged by morphologic examination and Wright-Giemsa staining. The cells were washed and resuspended in complete medium. Mononuclear cells having $<5 \%$ tumor cells as judged by morphologic examination of Wright-Giemsa-stained smears were accepted for use. The mean yield of mononuclear cells consisting of 80-95\% lymphocytes, 0-15\% monocyte/macrophages, and $0-5 \%$ tumor cells was $4.5 \times 10^{5} / \mathrm{ml}$.

Cell fractionation. Lymphocyte-rich mononuclear cells were fractionated as described elsewhere $(7,8,26)$. Mononuclear cells $\left(4 \times 10^{6} / \mathrm{ml}\right)$ were mixed with the same volume of $1 \%$ sheep erythrocyte suspension, incubated for $10 \mathrm{~min}$ at $37^{\circ} \mathrm{C}$, then centrifuged at $200 \mathrm{~g}$ for $5 \mathrm{~min}$, and further incubated at $4^{\circ} \mathrm{C}$ for $18 \mathrm{~h}$. The cell pellet was gently resuspended, and the suspension was layered over $15 \mathrm{ml}$ FicollHypaque in a $50-\mathrm{ml}$ polycarbonate tube and centrifuged at $400 \mathrm{~g} 30 \mathrm{~min}$ at $4^{\circ} \mathrm{C}$. The cells forming rosettes with sheep erythrocytes were collected from the bottom of the tube, treated with $0.83 \%$ Tris-buffered ammonium chrolide to lyse the attached erythrocytes, washed, and resuspended in complete medium. The cell preparation consisted of 90-97\% $\mathrm{T}$ cells as judged by rerosetting with sheep erythrocytes, $0-3 \%$ $B$ cells by determination of surface immunoglobulin-bearing cells with a direct immunofluorescence assay, and is hereafter referred to as $T$ cells. The unrosetted cells were collected from the interface, washed, rerosetted with sheep erythrocytes, and separated from rosetting cells by centrifugation on another Ficoll-Hypaque gradient. The sheep erythrocyte nonrosetting cells were collected from the interface, washed, and resuspended in complete medium. The cell preparation contained $36-65 \%$ B cells, $30-60 \%$ monocytes, and $0-5 \% \mathrm{~T}$ cells as judged by the above methods, and is hereafter referred to as non-T cells. Both cell preparations were $>96 \%$ viable according to the trypan blue dye exclusion test.

Autologous mixed lymphocyte cultures. Autologous mixed lymphocyte cultures were performed in triplicate using flatbottomed microtiter plates (Falcon Labware) with $1 \times 10^{5}$ responder $T$ cells and $1 \times 10^{5}$ mitomycin C-treated $(50 \mu \mathrm{g} /$ $\mathrm{ml}$ for $30 \mathrm{~min}$ ) stimulator non-T cells in a total volume of $0.2 \mathrm{ml}$, as described (18). Culture medium consisted of RPMI 1640 supplemented with $25 \mathrm{mM}$ Hepes, $2 \mathrm{mM}$ L-glutamine, $100 \mathrm{U}$ penicillin $/ \mathrm{ml}, 100 \mu \mathrm{g}$ streptomycin $/ \mathrm{ml}$ and heat-inactivated human AB serum. Cultures were incubated for $144 \mathrm{~h}$ at $37^{\circ} \mathrm{C}$ in a humidified atmosphere of $5 \% \mathrm{CO}_{2}$ in air. $1 \mu \mathrm{Ci}\left[{ }^{3} \mathrm{H}\right]$ thymidine $(5 \mathrm{Ci} / \mathrm{mmol}$, Radiochemical Centre, Amersham, England) was added to each well for the last 20 $h$ of the culture. The cultures were harvested on filter papers by a multiple automated sample harvester (MASH II, Microbiological Associates, Bethesda, MD). The incorporation of tritiated thymidine into newly synthesized DNA was measured with a liquid scintilation counter (Packard Instrument Co., Inc., Downers Grove, IL). The results are expressed as the difference between the counts per minute of responding cells in the presence and absence of stimulating cells $(\Delta \mathrm{cpm})$

Autorosette-forming cells. After mononuclear cells were isolated from the peripheral blood (see above), the remaining erythrocytes were collected, washed three times in phosphate-bufferred saline, and resuspended in RPMI 1640 into $1 \%$ cell suspension as described (18). Mononuclear cells at a concentration of $2 \times 10^{6} / \mathrm{ml}$ in $0.1 \mathrm{ml}$ RPMI 1640 were mixed with the same volume of autologous erythrocytes suspension and $0.2 \mathrm{ml}$ human $\mathrm{AB}$ serum. The mixture was incubated for $10 \mathrm{~min}$ at $37^{\circ} \mathrm{C}$, then centrifuged for $5 \mathrm{~min}$ at $200 \mathrm{~g}$, and further incubated for $2 \mathrm{~h}$ at $4^{\circ} \mathrm{C}$. The cell pellet was then gently resuspended, and one drop of the cell suspension was placed in a hemocytometer chamber, and $>200$ lymphocytes were counted under a microscopic examination. The percentage of lymphocytes forming rosettes with three or more erythrocytes was calculated.

To separate the autorosette-forming cells and nonrosetting cells, the autorosettes (see above) in $2 \mathrm{ml}$ RPMI 1640 supplemented with $50 \%$ human $A B$ serum were incubated for $18 \mathrm{~h}$ at $4^{\circ} \mathrm{C}$, then gently resuspended and layered on a FicollHypaque gradient as described (18). After centrifugation at $400 \mathrm{~g}$ for $30 \mathrm{~min}$, the autorosette-forming cells were collected from the pellet, gently resuspended in cold RPMI 1640 , and purified by another Ficoll-Hypaque centrifugation. The cell pellet was resuspended in warm RPMI 1640, incubated for $15 \mathrm{~min}$ at $37^{\circ} \mathrm{C}$, and then vortexed to disrupt the autorosettes. The cell suspension was layered on a warm Ficoll-Hypaque gradient and centrifuged for $15 \mathrm{~min}$ at 400 $g$ to eliminate the autologous erythrocytes. The cell suspension collected from the interface contained $75-97 \%$ autorosette-forming cells.

\section{RESULTS}

AMLR in peripheral blood and pleural effusion. The AMLR between T cells and non-T cells were studied in the peripheral blood of 20 normal donors, in the peripheral blood and carcinomatous pleural effusions of 20 patients with lung cancer, and in nonmalignant pleural effusions of 8 patients with congestive heart failure (Fig. 1). Blood T cells from normal controls vigorously responded to autologous non-T cells with 


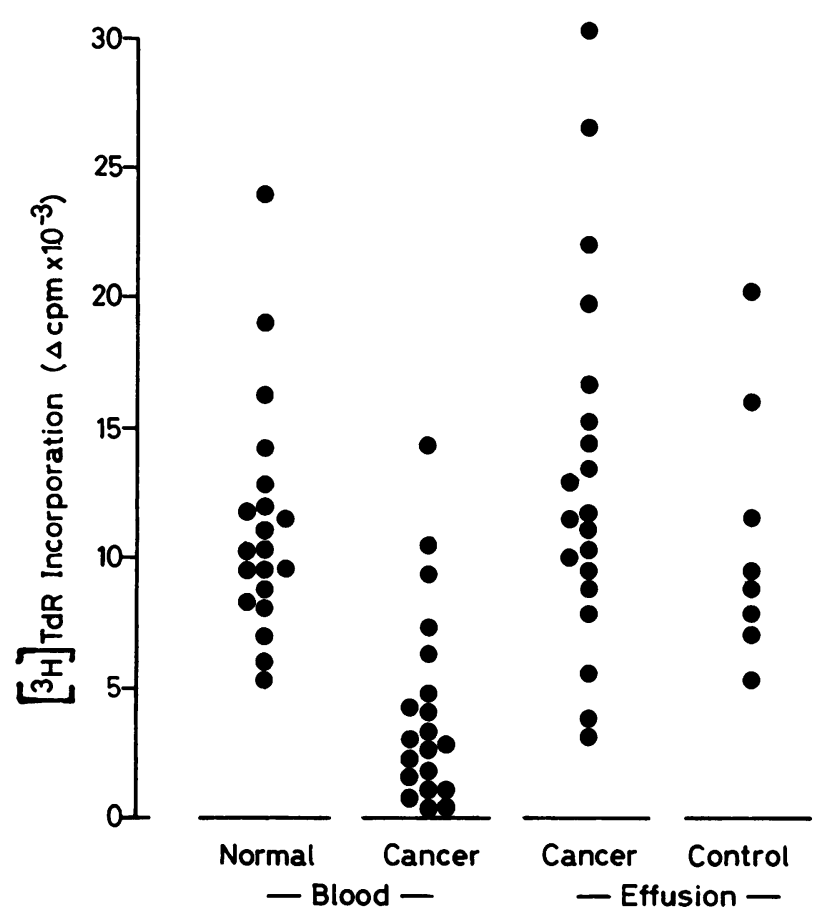

Figure 1 AMLR in the peripheral blood of normal donors and cancer patients and in pleural effusions of cancer patients and nonmalignant patients. $1 \times 10^{5} \mathrm{~T}$ cells were cultured with $1 \times 10^{5}$ autologous non-T cells for $6 \mathrm{~d}$. Results are expressed as mean $\Delta \mathrm{cpm}$ of triplicate samples.

the mean response of $11,221 \pm 4,156 \Delta \mathrm{cpm}(5,000$ $24,000 \Delta \mathrm{cpm})$. In contrast, the peripheral blood of cancer patients showed impairment of AMLR with the average response being $4,159 \pm 3,878 \Delta \mathrm{cpm}$. This mean value is significantly different from that of normal controls $(P<0.001)$. Effusion $T$ cells from the same cancer patients strongly proliferated in response to autologous eff usion non-T cells with the mean response of $13,257 \pm 7,075 \Delta \mathrm{cpm}$, which was comparable to or even higher than that of normal blood and control nonmalignant pleural effusions $(10,870 \pm 5,013 \Delta \mathrm{cpm})$. The AMLR of malignant pleural effusions was always higher than that of the peripheral blood of the same cancer patients and the mean value of the effusions was significantly different from that of the blood ( $P$ $<0.001)$. There were no significant differences in the background counts per minute of blood lymphocytes from normal donors and cancer patients and effusion lymphocytes from cancer patients and nonmalignant patients. These results indicate that the AMLR is impaired in the peripheral blood of advanced lung cancer patients but normal or even higher in their pleural effusions.

Kinetics of AMLR. The possibility that delayed or accelerated kinetics of AMLR might be responsible for the depression of blood AMLR of cancer patients was considered. Kinetic studies in which T cells were stimulated by autologous non- $T$ cells for time intervals varying from 0 to $9 \mathrm{~d}$ revealed that $\left({ }^{3} \mathrm{H}\right)$-thymidine incorporation became noticeable on day 5 , peaked on days 6-8, then decreased (Fig. 2). No significant differences were observed in kinetics of AMLR of the peripheral blood of normal controls and in the peripheral blood and pleural eff usions of cancer patients, indicating that the impairment of blood AMLR of cancer patients cannot be explained by altered kinetics.

AMLR between blood and effusion cells. To examine whether the depression of AMLR in the peripheral blood of cancer patients is attributable to a defect of responding $T$ cells, stimulating non- $T$ cells, or both, AMLR was performed between blood and effusion lymphocytes from the same patients. In these studies blood $T$ cells and eff usion $T$ cells were cultured with the same number of autologous non- $T$ cells from either peripheral blood or pleural effusions for $6 \mathrm{~d}$ (Table I). Effusion $\mathrm{T}$ cells responded to autologous blood non-T cells as vigorously as to autologous effusion non-T cells, suggesting that the capacity to stimulate autologous $T$ cells of non- $T$ cells from cancer patients is not affected and the non-T cell population has no suppressive activity to AMLR. On the other hand, blood $T$ cells from the patients failed to proliferate in response to autologous non-T cells from both

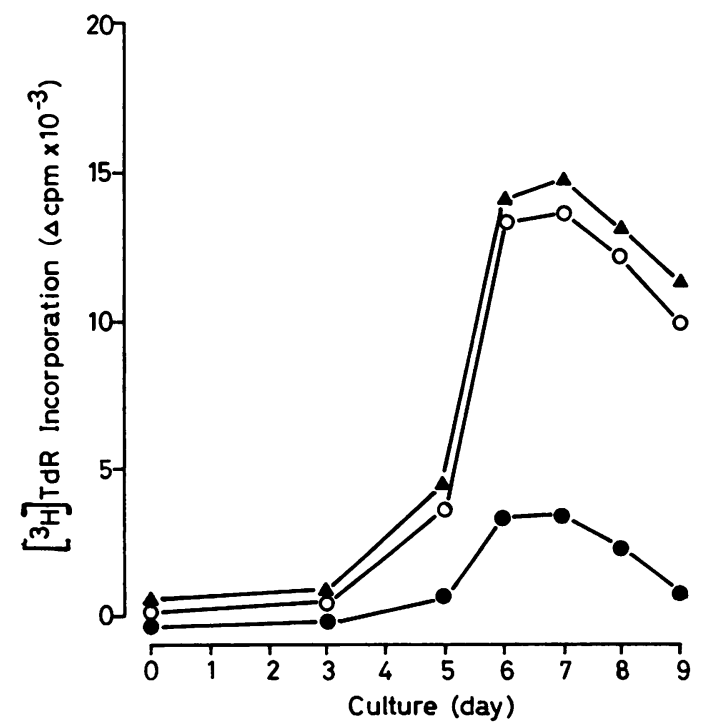

Figure 2 Kinetics of AMLR in normal donors and cancer patients. Cultures between $1 \times 10^{5} \mathrm{~T}$ cells and $1 \times 10^{5}$ non$T$ cells from the blood of a normal donor $(\Delta)$ and the blood $(\bullet)$ and effusions $(O)$ of a cancer patient were harvested on days $0,3,5,6,7,8$, and 9 . Results represent mean $\Delta \mathrm{cpm}$ of triplicate cultures. Similar results were obtained in four different experiments. 
TABLE I

AMLR between Blood and Effusion Lymphocytes

\begin{tabular}{cccc}
\hline \multirow{2}{*}{ Patient } & $\begin{array}{c}\text { Responding } \\
\text { T cells }\end{array}$ & Plood non-T cells & Effusion non-T cells \\
\cline { 3 - 4 } & & $\Delta c p m$ & $\Delta c p m$ \\
& & $3,153 \pm 293$ & $2,820 \pm 432$ \\
1 & Blood & $13,916 \pm 1,429$ & $12,956 \pm 1,853$ \\
& effusion & $968 \pm 132$ & $1,204 \pm 118$ \\
2 & Blood & $7,808 \pm 712$ & $8,774 \pm 969$ \\
& effusion & $4,352 \pm 631$ & $4,708 \pm 492$ \\
3 & Blood & $16,315 \pm 2,154$ & $14,493 \pm 1,438$ \\
& effusion & $389 \pm 82$ & $547 \pm 106$ \\
4 & Blood & $3,508 \pm 473$ & $2,968 \pm 265$ \\
& effusion & & $2,297 \pm 179$ \\
5 & Blood & $2,490 \pm 222$ & $11,810 \pm 1,404$ \\
& effusion & $11,224 \pm 1,315$ & $1,637 \pm 148$ \\
6 & Blood & $1,415 \pm 186$ & $5,688 \pm 705$ \\
\hline
\end{tabular}

Blood and effusion $\mathrm{T}$ cells were cultured for $6 \mathrm{~d}$ with either blood or effusion non- $T$ cells from the same patients, and the reactivity was measured by the incorporation of $\left[{ }^{3} \mathrm{H}\right]$ thymidine into DNA. Results are expressed as mean $\Delta \mathrm{cpm} \pm \mathrm{SD}$ for triplicate samples.

peripheral blood and pleural effusions. These results indicate that the responding $\mathrm{T}$ cell population but not the stimulating non-T cell population is responsible for the impairment of AMLR in the peripheral blood of cancer patients.

Possible role of suppressor cells. To test the possible presence of cells capable of suppressing AMLR in the circulation of cancer patients, effusion AMLR was performed in the presence or absence of blood lymphocytes from the same patients. The addition of either untreated or mitomycin-treated blood $\mathrm{T}$ cells resulted in no inhibition of eff usion AMLR of the same patients (Table II). The blood T cell populations were also found not to contain suppressor cells for AMLR as described above. These results suggest that the impairment of blood AMLR of cancer patients is not attributable to the presence of suppressor cells in their circulation.

Role of autorosette-forming cells in AMLR. As lymphocytes forming rosettes with autologous erythrocytes have been shown to respond in AMLR $(18,19)$, the frequency of autorosette-forming cells in the responding $T$ cell population was determined. The number of blood $T$ cells binding autologous erythrocytes from cancer patients averaged $16 \pm 9 \%$, which was significantly lower $(P<0.001)$ than that of normal controls $(31 \pm 11 \%)$. In contrast, the percentage of autorosette-forming cells of eff usion $\mathrm{T}$ cells $(34 \pm 12 \%)$ was
TABLE II

Effect of Blood T Cells on Effusion AMLR

\begin{tabular}{cccc}
\hline & \multicolumn{3}{c}{ ['HThymidine incorporation } \\
\cline { 2 - 4 } Patient & Effusion AMLR & $\begin{array}{c}\text { Untreated blood } \\
\text { T cells added }\end{array}$ & $\begin{array}{c}\text { Mitomycin-treated } \\
\text { blood T cells added }\end{array}$ \\
\hline & \multicolumn{4}{c}{} \\
1 & $16,741 \pm 1,558$ & $17,541 \pm 1,378$ & $16,537 \pm 1,592$ \\
2 & $3,863 \pm 499$ & $4,527 \pm 689$ & $4,108 \pm 391$ \\
3 & $21,926 \pm 2,183$ & $22,573 \pm 2,368$ & $21,716 \pm 1,748$ \\
4 & $13,402 \pm 1,433$ & $14,495 \pm 1,582$ & $12,579 \pm 1,356$ \\
5 & $9,405 \pm 773$ & $10,420 \pm 967$ & $9,849 \pm 847$ \\
6 & $15,380 \pm 1,644$ & $14,516 \pm 1,584$ & $15,283 \pm 1,732$ \\
\hline
\end{tabular}

Effusion T cells were cultured with the same number of autologous effusion non-T cells either in the presence or absence of the same number of mitomycin-treated or untreated autologous blood $\mathrm{T}$ cells for $6 \mathrm{~d}$. Results are expressed as mean $\Delta \mathrm{cpm} \pm \mathrm{SD}$ of triplicate samples.

comparable to that of normal blood $T$ cells and always higher than that of blood $T$ cells from the same patients. Then, the response index that indicates $\left[{ }^{3} \mathrm{H}\right]$ thymidine incorporation per autorosette-forming cell in AMLR was calculated (Fig. 3). No significant differences were observed in the response indices of

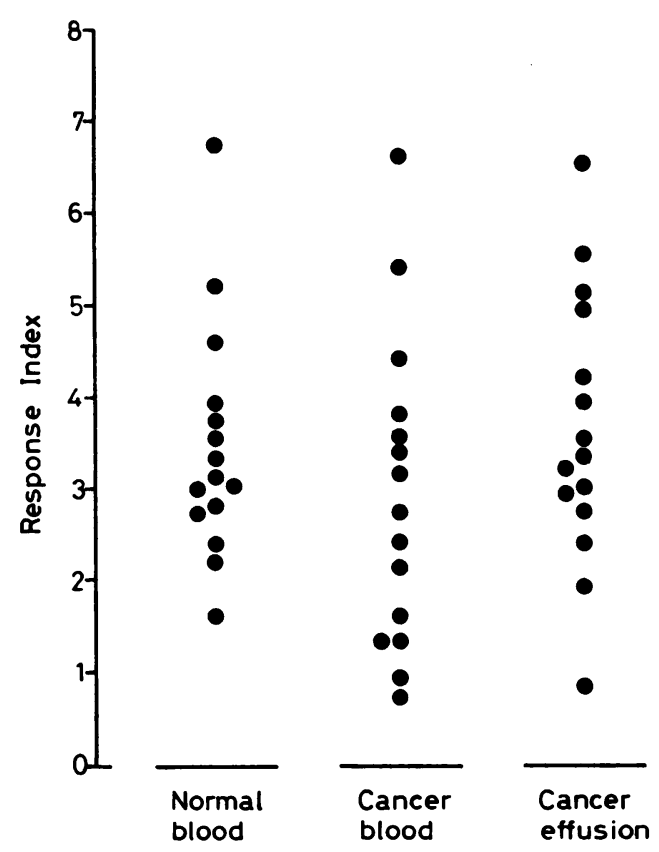

Figure 3 AMLR expressed in response index in normal donors and cancer patients. $1 \times 10^{5} \mathrm{~T}$ cells were cultured with $1 \times 10^{5}$ autologous non-T cells for $6 \mathrm{~d}$ and the reactivity was expressed in response index calculated as follows: response index $=\left(\left[{ }^{3} \mathrm{H}\right]\right.$ thymidine incorporation by $1 \times 10^{5} \mathrm{~T}$ cells) $/\left(\right.$ percentage of autorosette-forming cells $\times 10^{-2} \times 10^{5}$ ). 
blood lymphocytes from normal donors and blood and effusion lymphocytes from cancer patients, while tritiated thymidine incorporation by $T$ cells was significantly lower in the blood of cancer patients than in the blood of normal donors and in the effusions of the patients. These results suggest that the depression of blood AMLR of cancer patients results from the reduction of number of $\mathrm{T}$ cells forming rosettes with autologous erythrocytes.

To confirm the above suggestion, autorosette-forming cells were purified by density gradient centrifugation and cultured for $6 \mathrm{~d}$ with the same number of autologous non-T cells (Table III). The cell population enriched for autorosette-forming cells vigorously responded in the AMLR. There was no significant difference in tritiated thymidine incorporation by autorosette-forming cells from the peripheral blood of normal donors and from the peripheral blood and pleural effusions of cancer patients, while tritiated thymidine incorporation by blood $\mathrm{T}$ cells of cancer patients was depressed.

\section{DISCUSSION}

This paper has demonstrated that $T$ cells from the peripheral blood of patients with advanced lung cancer poorly respond to autologous non- $T$ cells while $T$ cells from carcinomatous pleural eff usions of the same patients vigorously proliferate in response to autologous non-T cells. The impaired blood AMLR of cancer patients seems to be derived from the disease itself because the patients had no previous history of anticancer chemotherapy or radiation therapy at the time of the study and were $<50 \mathrm{yr}$ old. Similarly, pronounced depression of AMLR has been reported in the peripheral blood of patients with systemic lupus erythematosus $(20,21)$, chronic lymphocytic leukemia (22), Hodgkin's disease (23), infectious mononucleosis (28), and Sjögren's syndrome (24).

TABLE III

Response of Autorosette-forming Cells in AMLR

\begin{tabular}{lcc}
\hline & \multicolumn{2}{c}{$\left[^{3}\right.$ H Thymidine incorporation } \\
\cline { 2 - 3 } & \multicolumn{1}{c}{ T cells } & Autorosetting cells \\
\hline & & $\Delta c p m$ \\
Normal blood & $10,982 \pm 3,487$ & $16,028 \pm 4,593$ \\
Cancer blood & $4,645 \pm 3,425^{\circ}$ & $12,175 \pm 3,965$ \\
Cancer effusion & $13,420 \pm 7,439$ & $17,239 \pm 6,701$ \\
\hline
\end{tabular}

T cells and autorosette-forming cells $\left(1 \times 10^{5}\right)$ were cultured with the same number of autologous non-T cells for $6 \mathrm{~d}$. Results are expressed as mean $\pm \mathrm{SD}$ of five individuals.

- Value is significantly lower compared to other groups by Student's $t$ test $(P<0.05)$
It is difficult but important to know which cell population is involved in the impairment of AMLR in patients because both responder $T$ cells and stimulator non-T cells are from the same patients. For the exact determination some investigators have used mixing experiments between patients and their healthy HLAidentical siblings and reported that the depressed AMLR in patients with systemic lupus erythematosus is attributed to defective stimulator non- $T$ cells in three cases (21), and the impaired AMLR in patients with Hodgkin's disease is due to the responder $T$ cell population in two cases (23). However, the usage of such mixing experiments between patients and their healthy HLA-identical siblings is generally limited because of the limited number of HLA-identical siblings. In our study we have performed mixing experiments between lymphocytes from the peripheral blood and pleural effusions of the same patients in most cases. Effusion $T$ cells from cancer patients vigorously responded to autologous blood non-T cells as well as autologous effusion non- $T$ cells. In contrast, blood $T$ cells failed to proliferate in response to both blood and effusion non-T cells from the same cancer patients. The findings indicate that the defect in the peripheral blood of cancer patients is in the responding $T$ cell population rather than in the stimulating non-T cells.

The presence of blood lymphocytes from cancer patients was found not to inhibit the AMLR of effusion lymphocytes from the same patients. The findings suggest that suppressor cells are not involved in the impaired blood AMLR of cancer patients. It might be possible that effusion $\mathrm{T}$ cells are already activated and then blood $T$ cells cannot inhibit their proliferation in AMLR. However, proliferative response to mitogens and alloantigens of effusion $T$ cells has been shown to be suppressed by blood $T$ cells of the same cancer patients (26). Furthermore, pretreatment of blood T cells from cancer patients and normal donors with OKT8 monoclonal antibody (defining suppressor/cytotoxic $\mathrm{T}$ cells) in the presence of complement did not augment their response in AMLR (data not shown). This is in agreement with other observations that treatment of $\mathrm{T}$ cells from normal donors with OKT8 antibody and complement has no (or slight) inhibitory effect on their proliferative response in AMLR (29).

It has recently been demonstrated that $T$ cells forming rosettes with autologous erythrocytes proliferate in response to autologous non-T cells in AMLR (18, $19,30)$. The number of autorosette-forming cells in the responding $T$ cell population was significantly lower in the peripheral blood of cancer patients than in the blood of normal individuals and in the pleural eff usions of the patients. When the response index was calculated by dividing $\left[{ }^{3} \mathrm{H}\right]$ thymidine incorporation by $\mathrm{T}$ cells by the number of autorosette-forming cells, 
there was no significant difference in the response indices in the blood of normal donors and in the blood and effusions of cancer patients. Then, AMLR was performed between autorosette-forming cells and autologous non-T cells. The cell population enriched for autorosette-forming cells of the peripheral blood of cancer patients responded to autologous non- $T$ cells as strongly as that of the blood of normal controls and that of the effusions of the same patients. It is evident from these findings that the reduction of number of autorosette-forming cells is responsible for the impaired AMLR in the peripheral blood of cancer patients.

This study has demonstrated that the AMLR in carcinomatous pleural effusions is comparable to or even higher than that in the peripheral blood of normal controls and that in nonmalignant pleural eff usions of patients with congestive heart failure. Normal or higher levels of AMLR in malignant effusions is unlikely to be due to the contamination of tumor cells in the stimulator non- $T$ cell population because eff $u$ sion $\mathrm{T}$ cells responded to autologous blood non- $\mathrm{T}$ cells as strongly as to autologous effusion non-T cells. In addition, the frequency of autorosette-forming cells in the responder $T$ cell population of pleural effusions of cancer patients was higher than that of their peripheral blood and similar to, or higher than that of normal donors. Furthermore, in patients with advanced lung cancer effusion, $T$ cells have been shown to be able to mediate suppressor function after activation with concanavalin $A$, whereas blood $T$ cells are not (26). These findings are in keeping with previous reports that $T$ cells capable of responding to autologous non- $T$ cells are enriched in $T$ cells capable of proliferating (24) and developing suppressor activity in response to concanavalin A $(15,18)$.

It has been demonstrated that the AMLR provides a proliferative stimulus for the generation of cytotoxic $\mathrm{T}$ cells $(11,30)$ and represents a defense mechanism against neoplastic transformation (12). Although the actual biological significance of the phenomenon is unclear, it may be important in host resistance against autologous tumor cells. The most potent antitumor activity may logically be expected to be present within or around the site of tumor growth. Therefore, it seems likely that the high AMLR in carcinomatous pleural effusions and low AMLR in the peripheral blood of cancer patients result from the migration of autoreactive $T$ cells from the circulation into the site of tumor growth.

\section{REFERENCES}

1. Golub, S. H., T. X. O'Connel, and D. L. Morton. 1974 Correlation of in vivo and in vitro assays of immuno- competence in cancer patients. Cancer Res. 34: 18331837.

2. Uchida, A., and T. Hoshino. 1980. Clinical studies on cell-mediated immunity in patients with malignant disease. I. Effect of immunotherapy with OK-432 on lymphocyte subpopulation and phytomitogen responsiveness in vitro. Cancer (Phila.). 45: 476-483.

3. Rees, J. C., J. L. Rossio, H. G. Wilson, J. P. Minton, and M. C. Dodd. 1975. Cellular immunity in neoplasia. Antigen and mitogen responses in patients with bronchogenic carcinoma. Cancer (Phila.). 36: 2010-2015.

4. Dean, J. H., R. Connor, R. B. Herberman, J. Silva, J. L. McCoy, and R. K. Oldham. 1977. The relative proliferation index as a more sensitive parameter for evaluating lymphoproliferative responses of cancer patients to mitogens and alloantigens. Int. J. Cancer 20: 359370 .

5. Zembala, M., B. Mytar, T. Popiela, and G. L. Asherson. 1977. Depressed in vitro peripheral blood lymphocyte response to mitogens in cancer patients. The role of suppressor cells. Int. J. Cancer. 19: 605-613.

6. Jerrells, T. R., J. H. Dean, G. L. Richardson, J. L. McCoy, and R. B. Herberman. 1978. Role of suppressor cells in depression of in vitro lymphoproliferative responses of lung cancer and breast cancer patients. J. Natl. Cancer Inst. 61: 1001-1009.

7. Uchida, A., and T. Hoshino. 1980. Clinical studies on cell-mediated immunity in patients with malignant disease. II. Suppressor cells in patients with cancer. Cancer Immunol. Immunother. 9: 153-158.

8. Uchida, A., and T. Hoshino. 1980. Reduction of suppressor cells in cancer patients treated with $\mathrm{OK}-432 \mathrm{im}-$ munotherapy. Int. J. Cancer 26: 401-404.

9. Opelz, G. K., M. Kiuchi, M. Takasugi, and P. I. Terasaki. 1975. Autologous stimulation of human lymphocyte subpopulations. J. Exp. Med. 142: 1327-1333.

10. Kuntz, M. M., J. B. Innes, and M. E. Weksler. 1976 Lymphocyte transformation induced by autologous cells IV. Human T lymphocyte proliferation induced by autologous or allogeneic non-T lymphocytes. J. Exp. Med. 143: 1042-1054.

11. Weksler, M. E., and R. Kozak. 1977. Lymphocyte transformation induced by autologous cells. V. Generation of immunologic memory and specificity during the autologous mixed lymphocyte reaction. J. Exp. Med. 146: 1833-1838.

12. Weksler, M. E., and G. Birnbaum. 1972. Lymphocyte transformation induced by autologous cells. Stimulation by cultured lymphoblast line. J. Clin. Invest. 51: 31243132

13. Hausman, P. B., and J. D. Stobo. 1979. Specificity and function of a human autologous reactive T cell. $J$. Exp. Med. 149: 1537-1542.

14. Smith, J. B., and K. P. Knowlton. 1979. Activation of suppressor $\mathrm{T}$ cells in human autologous immune lymphocyte culture. J. Immunol. 123: 419-422.

15. Sakane, T., and I. Green. 1979. Specificity and suppressor function of human $T$ cells responsive to autologous non-T cells. J. Immunol. 123: 583-589.

16. Takasugi, M., M. Kiuchi, and G. Opelz. 1977. Lymphocyte interactions in autologous and allogeneic reactions. Transplant Proc. 9: 789-792.

17. Beale, M. G., R. P. Macdermott, M. C. Stacey, G. S. Nash, B. H. Hahn, M. V. Seiden, S. L. B. Jacobs, and L. S. P. Loewenstein. 1980. Simulating cell types in the autologous mixed lymphocyte reaction in man. J. Immunol. 124: 227-232. 
18. Uchida, A., and M. Micksche. 1981. Reactivity to autologous non-T cells and suppressor function of human autologous rosettes. Immunol. Lett. 3: 145-149.

19. Palacios, R., L. Llorente, and D. Alarcon-Secovia. 1980 Autologous rosette-forming $T$ cells as the responding cells in human autologous mixed lymphocyte reaction. J. Clin. Invest. 65: 1527-1530.

20. Sakane, T., A. D. Steinberg, and I. Green. 1978. Failure of autologous mixed lymphocyte reactions between $T$ and non-T cells in patients with systemic lupus erythematosus. Proc. Natl. Acad. Sci. U. S. A. 75: 3464-3468.

21. Kuntz, M. M., J. B. Innes, and M. W. Weksler. 1979 The cellular basis of the impaired autologous mixed lymphocyte reaction in patients with systemic lupus erythematosus. J. Clin. Invest. 63: 151-153.

22. Smith, J. B., K. P. Knowlton, and L. S. Koons. 1977. Immunologic studies in chronic lymphocytic leukemia defective stimulation of $\mathrm{T}$ cell proliferation in autologous mixed lymphocyte culture. J. Natl. Cancer Inst. 58: 579-585.

23. Engleman, E. G., C. J. Benike, R. T. Hope, H. S. Kaplan, and F. R. Berberich. 1980. Autologous mixed lymphocyte reaction in patients with Hodgkin's disease. J. Clin. Invest. 66: 149-158.

24. Miyasaka, N., B. Sauvezie, D. A. Pierce, T. E. Daniels, and N. Talal. 1980. Decreased autologous mixed lymphocyte reaction in Sjögren's syndrome. J. Clin. Invest. 66: $928-933$.
25. Böyum, A. 1968. Isolation of mononuclear cells and granulocytes from human blood. Scand. J. Clin. Lab. Invest. 21 (Suppl. 97): 77-89.

26. Uchida, A., and M. Micksche. 1981. Concanavalin Ainducible suppressor cells in pleural effusions and peripheral blood of cancer patients. Cancer Immunol. Immunother. 10: 203-210.

27. Uchida, A., and M. Micksche. 1981. Natural killer cells in carcinomatous pleural effusions. Cancer Immunol. Immunother. 11: 131-138.

28. Moody, C. E., B. A. Casazza, W. N. Christenson, and M. E. Weksler. 1979. Lymphocyte transformation induced by autologous cells. VIII. Impaired autologous mixed lymphocyte reactivity in patients with acute infectious mononucleosis. J. Exp. Med. 150: 1448-1455.

29. Damle, N. K., J. A. Hansen, R. A. Good, and S. Gupta. 1981. Monoclonal antibody analysis of human T lymphocyte subpopulation exhibiting autologous mixed lymphocyte reaction. Proc. Natl. Acad. Sci. U.S.A. 78: 50965098.

30. Fournier, C., and J. Charreire. 1981. Autologous mixed lymphocyte reaction in man. I. Relationship with age and sex. Cell Immunol. 60: 212-219.

31. Van de Stouwe, R. A., H. G. Kunkel, J. P. Halper, and M. E. Weksler. 1977. Autologous mixed lymphocyte culture reactions and generation of cytotoxic T cells. J. Exp. Med. 148: 1909-1914. 